\title{
MORFOLOGIA Y ESTRATEGIAS REPRODUCTIVAS DEL GAMETOFITO DE POLYPODIUM LEPIDOTRICHUM (FEE) MAXON (POLYPODIACEAE)
}

\author{
IRMa ReYes JaRAmiLlo \\ $Y$ \\ Blanca Perez-Garcia \\ Universidad Autónoma Metropolitana-Iztapalapa \\ Departamento de Biología \\ Apdo. Postal 55-535 \\ 09340 México, D.F.
}

\section{RESUMEN}

El gametofito joven de Polypodium lepidotrichum (Fée) Maxon es un filamento corto constituido por cuatro a cinco células; en una fase intermedia los gametofitos son espatulados. Los protalos maduros, formados alrededor de ocho semanas después de la germinación de las esporas, son cordiformes, reniformes $u$ ovales con la base angosta. Se observaron gametofitos bisexuados y unisexuados. Los esporofitos jóvenes fueron evidentes después de doce semanas a partir de la siembra de las esporas.

Se concluye que las estrategias reproductivas de $P$. lepidotrichum involucran fecundación intragametofítica e intergametofítica.

\section{ABSTRACT}

The young prothallus of Polypodium lepidotrichum (Fée) Maxon is a short filament with four to five cells. Later on, the thallus is spathulate. The mature thallus, about eight weeks after germination, is cordate, reniform or ovate with a narrow base. Bisexual and unisexual gametophytes were produced. Young sporophytes were observed twelve weeks after the spore were sown.

It is concluded that the reproductive strategies of P. lepidotrichum include intragametophytic and intergametophytic fertilization.

\section{INTRODUCCION}

El presente estudio es una contribución al conocimiento de la fase gametofítica de las Polypodiaceae de distribución geográfica neotropical.

Entre los trabajos escritos sobre morfogénesis del talo gametofítico de Polypodiaceae destacan los de Hartman (1931), Davie (1951), Stokey (1959), Nayar (1962), Atkinson y Stokey (1970).

$P$. lepidotrichum (Fée) Maxon es un helecho epífito que crece en altitudes entre 1300 y 1600 m s.n.m., no es abundante; en México sólo ha sido recolectado en pequeñas áreas en los estados de Hidalgo, Veracruz y Oaxaca (Smith, 1981; Mickel y Beitel, 1988).

Esta especie la ubica taxonómicamente de la Sota (1966) en el grupo Polypodium squamatum, y Tryon y Tryon (1982) en el de Polypodium lepidopteris. 


\section{MATERIAL Y METODO}

Se recolectaron plantas fértiles de Polypodium lepidotrichum (Fée) Maxon en Tianguistengo, Hidalgo. Los ejemplares de respaldo se encuentran en UAMIZ (Pérez-García 755).

Las esporas se obtuvieron de hojas fértiles de diferentes individuos, las cuales se metieron en sobres de papel, se secaron al aire libre y se separaron por medio de una malla de $0.074 \mathrm{~mm}$ de diámetro.

Las esporas se sembraron sin tratamiento previo de esterilización, en 50 cajas de Petri de $5 \mathrm{~cm}$ de diámetro conteniendo medio de cultivo de Thompson (Klekowski, 1969) en condiciones asépticas. Con un pincel de pocas cerdas, se esparcieron sobre la superficie del medio. La densidad de siembra fue un promedio de 450 esporas por centímetro cuadrado y el porcentaje de germinación fue de $95 \%$.

Los cultivos se incubaron en condiciones de laboratorio con luz artificial (Solar 75 watts, luz de día), con un fotoperiodo de 12 hrs luz-oscuridad y temperatura de $20-28^{\circ} \mathrm{C}$; cuatro de las cajas se mantuvieron en la oscuridad durante el desarrollo del estudio. Los dibujos y fotomicrografías se obtuvieron de gametofitos vivos.

\section{OBSERVACIONES}

Las esporas de Polypodium lepidotrichum son monoletes (Fig. E) con papilas esparcidas en la cara proximal (Tryon y Lugardon, 1991), miden en promedio 52 x $36 \mu \mathrm{m}$.

La germinación se inició dos semanas después de la siembra. Al igual que en otras especies de Polypodiaceae se observaron glóbulos de aceite de color amarillo en las esporas puestas a germinar. Al formarse los primeros rizoides y dividirse las primeras células protálicas, estas gotas amarillas persisten en la primer célula del filamento germinativo y desaparecen al formarse la lámina (Figs. 1-6).

La cubierta de la espora permanece unida a la célula inicial del filamento germinativo incluso en fases adultas del gametofito.

El filamento germinativo es corto, se compone de una hilera de 4 a 5 células, las cuales excepto la inicial, se dividen longitudinalmente, dando lugar a la formación de la lámina del protalo de forma espatulada (Figs. 7-9). Los rizoides son de color pardo claro.

En la tercera semana los protalos presentan una célula obcónica apical (Fig. 7), a partir de la cual y en un tiempo aproximado de 15 días, se forma un meristemo pluricelular (Figs. 10-16).

Los protalos de esta especie son desnudos en las primeras fases de crecimiento, pero después de adquirir la forma espatulada, desarrollan pelos de tipo unicelular simple (Figs. 11, 13, 14, 30), localizados principalmente en el margen de las alas y, en menor número, en la superficie.

A partir del segundo mes de la germinación de las esporas, los gametofitos adultos son cordiformes (Fig. 17), reniformes (Fig. 18) u ovales con base angosta (Figs. 19, 31). Los primeros presentan amplias alas isodiamétricas y un cojinete central bien definido, del cual a partir del segundo o tercer mes emergen numerosos arquegonios (Fig. 25), cuyos cuellos exhiben cuatro hileras de células cada uno, orientados en sentido opuesto a la región 
Reyes y Pérez-García: Morfología y Estrategias Reproductivas de Polypodium lepidotrichum

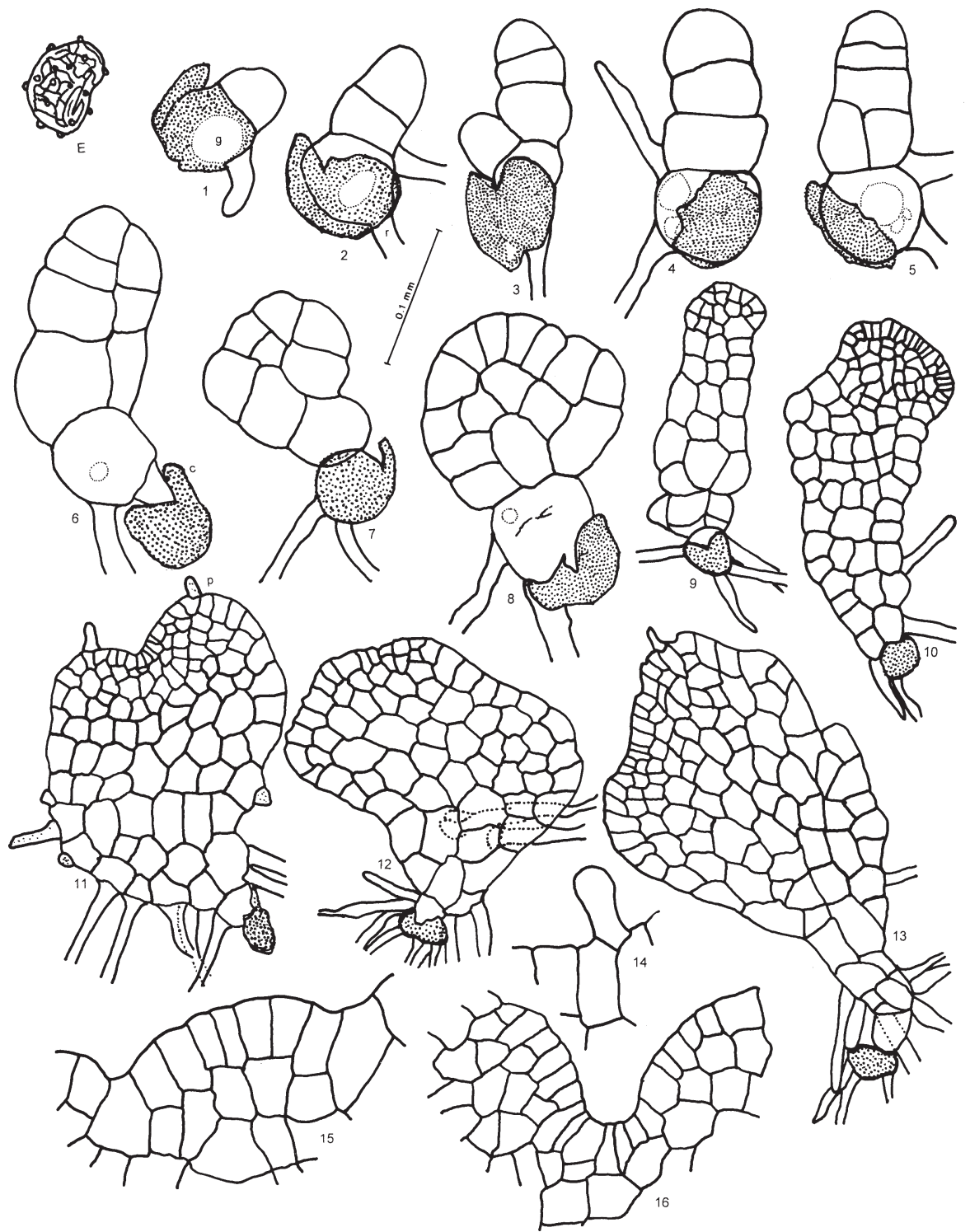

Figs. 1-16 y E. Desarrollo del protalo. E. Espora. Fig. 1. Germinación de la espora. Figs. 2-5. Filamentos germinativos. Figs. 6-10. Desarrollo de la lámina protálica. Figs. 11-13. Protalos espatulados jóvenes, 30 a 45 días. Fig. 14. Pelo marginal. Figs. 15-16. Meristemo pluricelular. g. Glóbulo de aceite; c. Cubierta de la espora; r. Rizoide; p. Pelo simple. 
apical del gametofito. Cabe mencionar que los arquegonios más jóvenes se observan próximos a la región apical y los más viejos en la región basal, cercana a los rizoides.

Los protalos ovales son comparativamente más pequeños que los descritos anteriormente (Figs. 19, 27, 31), con alas estrechas, no presentan tan marcada la muesca, ni el cojinete. Este tipo de protalo forma principalmente anteridios (Figs. 27, 31) y en pocas ocasiones se observaron escasos arquegonios (Fig. 19). Los anteridios son marginales y superficiales (Figs. 20, 28, 29, 31, 32), se diferencian en la región media y en ambas alas del protalo (Figs. 19, 27, 28, 30, 32).

A nivel de poblaciones de gametofitos, existen diferencias morfológicas significativas. En cajas de cultivo sembradas en la misma fecha y mantenidas bajo iguales condiciones, en algunas se desarrollaron gametofitos de forma espatulada y ovalada, con numerosos anteridios (Figs. 27, 32), mientras que en otras, la población estaba constituida por gametofitos cordiformes y reniformes maduros, algunos vegetativos y otros con numerosos arquegonios (Fig. 25).

En otros cultivos, crecieron protalos cordiformes vegetativos, otros con arquegonios, así como un número reducido (10\%) de gametofitos espatulados bisexuados, de tamaño pequeño.

Los anteridios de Polypodium lepidotrichum son de forma globosa, constituidos por tres células: basal, anular y opercular (Figs. 20, 21, 26-28, 30, 32) mostrando el desarrollo y estructura descritos para Polypodiaceae.

Hubo evidencias de formación de esporofitos a partir de los tres meses después de la siembra (Figs. 22, 23) en gametofitos cordiformes bisexuados, en los cordiformes arquegoniados y en los ovales anteridiados con escasos arquegonios.

\section{DISCUSION Y CONCLUSIONES}

Las esporas de Polypodium lepidotrichum en las condiciones de laboratorio descritas, germinan en menos tiempo que en las Polypodiaceae del Viejo Mundo mencionadas por Nayar (1962).

El filamento germinativo de Polypodium lepidotrichum, es más corto que el de Pleopeltis excavata T. Moore (6 células), Crypsinus griffithianus (Hook.) Copel. (9 células) y Arthromeris wallichiana (Spreng.) Ching (6-7 células). Los glóbulos de aceite amarillos y la persistencia de la cubierta de la espora unida a la base del filamento germinativo, son caracteres que comparten con otras Polypodiaceae.

Con relación al tiempo en que los gametofitos se vuelven cordiformes, y adquieren la madurez, Polypodium lepidotrichum lo hace más tempranamente (2.5 a 4 meses) en comparación con Campyloneurum angustifolium (Sw.) Fée y Pleopeltis excavata que se dilatan 3 a 5 meses.

Los anteridios, al igual que en Arthromeris wallichiana y Polypodium ammoenum, se diferencian entre los 2 y 3 meses. Su forma y estructura coincide con la descripción dada para otras Polypodiaceae (Davie, 1951; Nayar, 1962; Hartman, 1931). Con respecto a los protalos maduros, se encontraron variaciones en cuanto a forma y comportamiento sexual, que no se citan en otros trabajos.

En cultivos en que la población gametofítica se componía principalmente de protalos cordiformes arquegoniados, se desarrolló también un pequeño número de gametofitos 


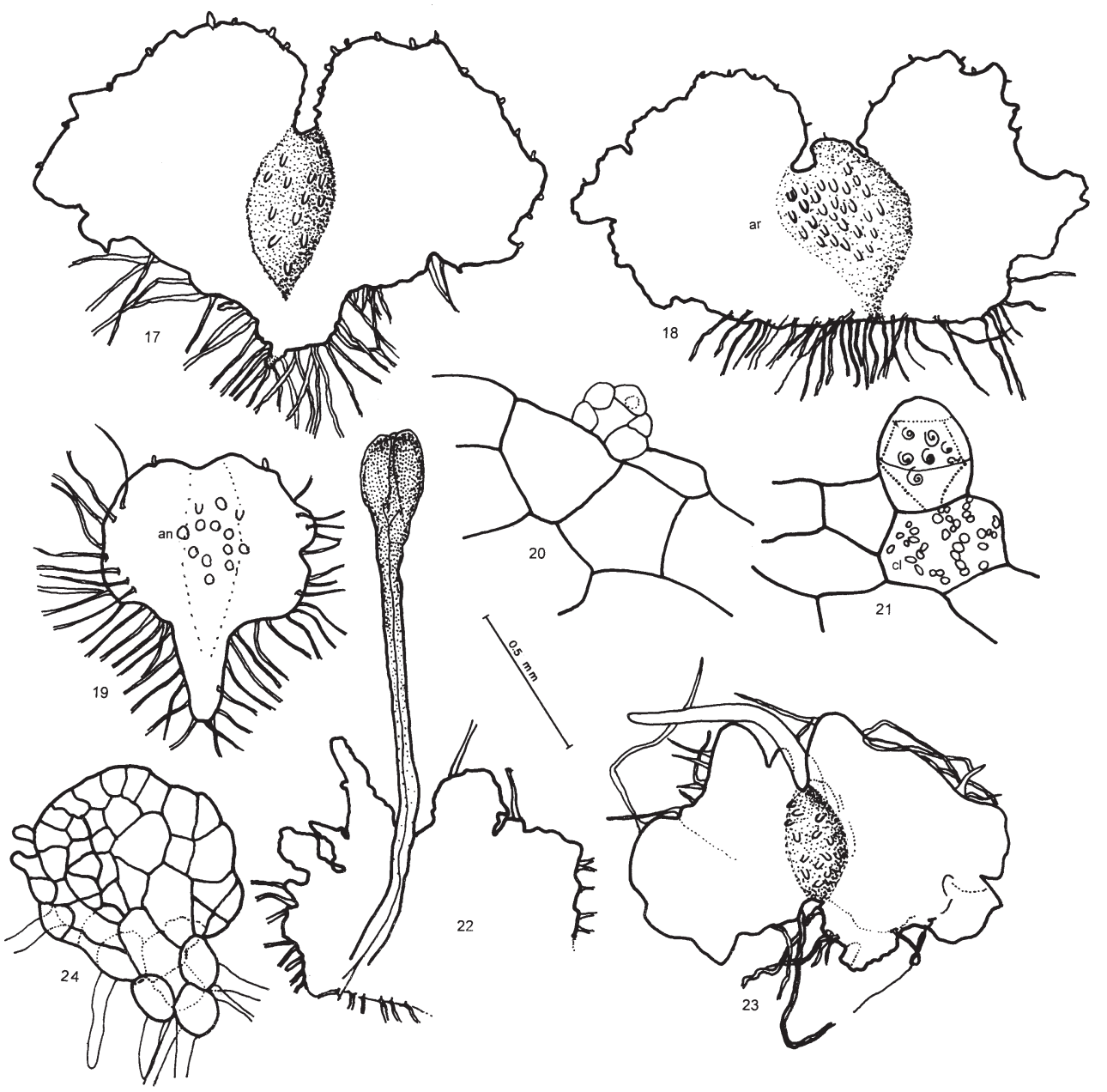

Figs. 17-24. Protalos maduros. Fig. 17. Cordiforme. Fig. 18. Reniforme. Fig. 19. Oval. Figs. 20-21. Anteridios. Figs. 22-23. Esporofitos incipientes, 135 días. Fig. 24. Gametofitos de 40 días diferenciándose por acción de anteridiógenos. an. Anteridios; ar. Arquegonios; cl. Cloroplastos. 

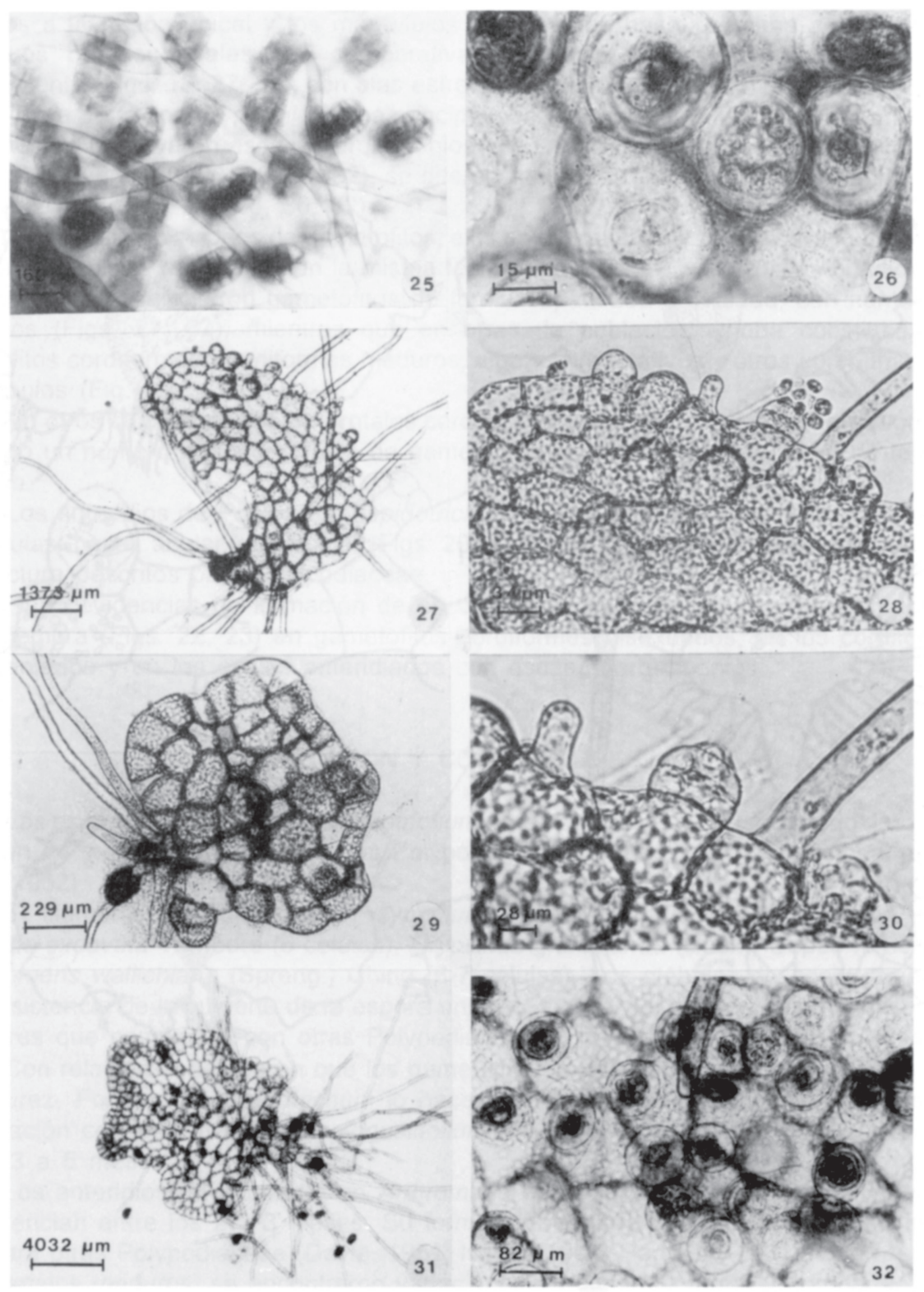

Figs. 25-32. Gametangios. Fig. 25. Cuellos de arquegonios, 110 días. Fig. 26. Vista superficial de anteridios. Fig. 27. Protalo anteridiado, 80 días. Figs. 28 y 30. Anteridios marginales. Fig. 29. Gametofito amerístico. Fig. 31. Protalo oval anteridiado, 105 días. Fig. 32. Anteridios del protalo oval (Fig. 31). 
masculinos precoces (Figs. 24, 29), de apariencia similar a los citados por Näf (1979), obtenidos mediante la inducción de anteridios por la aplicación controlada de anteridiógenos.

La actividad de anteridiógenos en diferentes especies de helechos ha sido dada a conocer por Voeller (1964), así como por Nester y Schedlbauer (1982) entre otros, y se ha registrado en alrededor de 20 especies, entre las que no se incluyen especies del género Polypodium (Raghavan, 1989; Näf, 1979).

La formación de protalos cordiformes arquegoniados y bisexuados, así como de gametofitos espatulados u ovalados masculinos, de menor tamaño que los primeros, sugieren diferentes estrategias reproductivas, de acuerdo con Klekowski (1969). Una de ellas es la reproducción sexual intragametofítica, es decir, la unión de anterozoide y oosfera del mismo gametofito. Este tipo de reproducción se considera como el más común entre los helechos homospóricos, de acuerdo con interpretaciones de varios autores (Raghavan, 1989).

La segunda estrategia reproductiva es la intergametofítica, la cual se deduce de la observación de protalos arquegoniados con esporofitos, resultando de la fusión de gametos formados en diferentes gametofitos.

Se sabe que la formación de gametangios en los protalos de helechos depende de varios factores, por ejemplo: concentración de nutrimentos, densidad de siembra de cultivo, cantidad y calidad de luz, pero se desconocen los mecanismos que determinan su diferenciación sexual (Raghavan, 1989). Después de estudiar el desarrollo de la fase gametofítica de $P$. lepidotrichum surgen algunos cuestionamientos: ¿Por qué en cajas de cultivo sembradas bajo las mismas condiciones de laboratorio y en el mismo día, en unas crecen poblaciones de gametofitos masculinos y en otras arquegoniados o bisexuales? ¿Cuál es el comportamiento sexual de la fase gametofítica de Polypodium lepidotrichum en condiciones de campo?

Finalmente, podemos concluir que esta especie presenta reproducción intragametofítica e intergametofítica, que le confiere mayor variación genética y que, a partir de que sus esporas son puestas en un medio adecuado para su germinación, completa su fase gametofítica e inicia la esporofítica en un período de 3 a 4 meses.

\section{AGRADECIMENTOS}

Las autoras agradecen a los Drs. Luis Diego Gómez y Ramón Riba sus comentarios y valiosas sugerencias al manuscrito.

\section{LITERATURA CITADA}

Atkinson, L. R. y A. G. Stokey. 1970. Gametophyte of Polypodium chnoodes. Phytomorphology 20: 363-367.

Davie, J. H. 1951. Development of antheridium in the Polypodiaceae. Amer. J. Bot. 38: 621-628.

De la Sota, E. R. 1966. Revisión de las especies americanas del grupo Polypodium squamatum L. Polypodiaceae (s. str.). Revista Mus. La Plata, Secc. Bot. 10: 69-186.

Hartman, M. E. 1931. Antheridial dehiscence in the Polypodiaceae. Bot. Gaz. 91: 252-276. 
Klekowski, E. J., Jr. 1969. Reproductive biology of the Pteridophyta III. A study of the Blechnaceae. J. Linn. Soc., Bot. 62: 361-377.

Mickel, J. T. y J. M. Beitel. 1988. Pteridophyte flora of Oaxaca, Mexico. Mem. New York Bot. Gard. 46: $1-568$.

Näf, V. 1979. Cap. 12. Antheridogens and antheridial development. In: Dyer, A. F. (ed.). The experimental biology of ferns. Academic Press. Londres. pp. 435-470.

Nayar, B. K. 1962. Morphology of spores and prothalli of some species of Polypodiaceae. Bot. Gaz. 123: 223-232.

Nester, J. E. y M. D. Schedlbauer. 1982. Antheridiogen activity of Anemia mexicana. Canad. J. Bot. 60: $1606-1610$.

Raghavan, V. 1989. Developmental biology of fern gametophytes. In: Barlow, P. W., D. Bray, P. B. Green y J. M. W. Slack (eds.). Developmental and cell biology series. Cambridge University Press. Cambridge. 361 pp.

Smith, A. R. 1981. Flora of Chiapas: Part 2. Pteridophytes. The California Academy of Sciences. San Francisco, California. 370 pp.

Stokey, A. G. 1959. Polypodium pectinatum and P. plumula - Polypodiaceae or Grammitidaceae ? Amer. Fern J. 49(1): 142-146.

Tryon, A. F. y B. Lugardon. 1991. Spores of the Pteridophytes: Surface, wall structure, and diversity based on electron microscope studies. Springer-Verlag. Nueva York. 648 pp.

Tryon, R. M. y A. F. Tryon. 1982. Ferns and allied plants with special reference to tropical America. Springer-Verlag. Nueva York. 662 pp.

Voeller, B. R. 1964. Antheridogens in ferns. In: Régulateurs naturels de la croissance végétale. Colloques Internationaux du Centre National de la Recherche Scientifique. Paris. 123: 665-684. 